\title{
Avaliação da Disciplina Observação da Prática Médica pelos Graduandos de Medicina da Unifesp - Escola Paulista de Medicina
}

\section{Medical Students' Assessment of the Course on Observation of Medical Practice at the Unifesp School of Medicine}

Juliana Augusta Plens de Moura Garcia Danielle Bianchini Rampim

Paulo Schor

Julieta Freitas Ramalho da Silval

PALAVRAS-CHAVE

- Relações Médico-Paciente.

- Estudantes de Medicina.

- Educação Médica.

- Ensino

KEYWORDS

- Doctor-Patient Relationship.

- Students, Medical.

- Medical Education.

- Teaching.

Recebido em: 15/12/2009

Aprovado em: 17/03/2010

\section{RESUMO}

Discute-se a necessidade de cuidar, no campo afetivo, das relações estabelecidas entre médicos e pacientes, o que depende de modelos de humanização durante o ensino médico. Em 2003, a Unifesp iniciou uma unidade curricular (UC) que propôs a Observação das Práticas Médicas (OPM) aos primeiranistas do curso médico. Após a observação, seguia-se uma discussão das experiências de modo expositivo e reflexivo, com professores de diversas subáreas. O objetivo do estudo foi avaliar a influência imediata e ao longo do tempo desta UC sobre 30 graduandos de Medicina do primeiro ao terceiro ano (dez por ano), utilizando um questionário de abordagem quantitativa (cinco questões de múltipla escolha) $e$ qualitativa (três questões abertas, categorizadas após análise e consenso dos dois autores). Concluiu-se que a UC permitiu a apresentação de práticas médicas aos iniciantes, que tinham pouco contato com as mesmas. Ao longo dos anos, observou-se uma modificação na percepção dos alunos sobre a OPM: os alunos das primeiras séries valorizaram o acolhimento emocional, enquanto os de séries mais adiantadas, o conhecimento do seu campo de aprendizado e atuação futura.

\section{ABSTRACT}

The article discusses the need to deal with physician-patient relations at the affective level, which requires models for humanization of care during undergraduate medical training. In 2003, the UNIFESP School of Medicine launched a course on Observation of Medical Practices as part of the regular curriculum for first-year medical students. The observation was followed by discussion of experiences with lectures, reflection, and debate with medical faculty from various specialties. The aim of the study was to assess the immediate and long-term impact of the course on the 30 first to third-year undergraduates (10 students per year), using a quantitative (5 multiple-choice questions) and qualitative questionnaire (3 open questions, categorized after analysis and consensus between the two authors). The authors concluded that the course allowed presentation of medical practices to the early medical undergraduates, who had little previous contact with this reality. Over the course of the years, a change was observed in the students' perception of Observation of Medical Practice: students in the initial years tended to value emotional support for patients, while as the years went by the undergraduates focused more on the knowledge in their field of learning and their future professional work. 
A história da medicina nada significa quando dissociada dos povos e das culturas em cujo meio tal prática se realiza. No ano de 1921 d.C., os gregos eram considerados criadores da arte de curar ${ }^{1}$, e a previsão refinada e sensível dos dilemas envolvidos na arte da cura era percebida através da criação do mito de Asclépio $^{2}$, que fora salvo do ventre da mãe, cujo corpo havia sido queimado. As dores teriam tornado Asclépio capaz de compreender todo o sofrimento dos doentes, encontrando remédio para todos os males e atraindo, assim, doentes e mutilados aos seus templos, em busca de cura ${ }^{3}$.

A arte da cura é apresentada de diferentes formas pelos mais diversos autores, como Alves ${ }^{4}$, que, em seu livro $O$ médico, afirma:

O corpo é um delicado instrumento musical. É preciso cuidar dele, para que ele produza música. Para isso, há uma infinidade de recursos médicos. [...] Médicos e enfermeiras são, ao mesmo tempo, técnicos e mágicos a quem é dada a missão de consertar os instrumentos e despertar neles vontade de viver[...]. (p. 9-10)

A opção profissional decorre da articulação de mecanismos psíquicos e sociais na subjetividade de cada indivíduo. É influenciada por idade, sexo, história de vida do sujeito e de sua família, e depende da classe social em que esses indivíduos estão inseridos ${ }^{5}$. Curiosidades sobre sexo, morte e tabus que a prática médica permite transgredir são comumente identificadas no processo analítico de médicos e estudantes de Medicina ${ }^{3}$. Muitas vezes, essa profissão é escolhida com a finalidade de se instrumentalizar para "dar vida ao outro", sendo a morte simbolizada pela enfermidade e personificada nos pacientes. O enfermo, par complementar do médico, é vivenciado como antítese do que o profissional passa a representar: saúde e vida. Por essa razão, o desempenho do papel se transforma numa constante, cujo objetivo é ser jovem, sadio, enfim, eternamente vivo, em oposição ao outro, o paciente envelhecido, enfermo e mortal ${ }^{6}$.

Na escolha da profissão, além de tais mecanismos, são importantes as motivações conscientes (desejo de compreender, de ver, desejo de contato, prestígio social e do saber, alívio prestado aos que sofrem, necessidade de ser útil, atração pelo dinheiro, pela responsabilidade ou pela reparação, desejo de uma profissão liberal e necessidade de segurança) e inconscientes ("identificação maior ou menor com os pais, o que leva a preservar e continuar seus valores"; "desejo de expiar impulsos agressivos - desejo que se manifesta pelo ato de curar, como reparação da agressividade"; "curiosidade inconsciente de conhecer o corpo da mãe"; "negação da morte").
Esses desejos conscientes e inconscientes são compartilhados: o desejo de reparação consciente pode ter origem na reparação da agressividade inconsciente, dirigida às figuras parentais durante as primeiras experiências de individualização e reconhecimento ${ }^{3}$.

O embate que se dá entre a idealização do papel médico e a realidade da formação profissional não é tranquilo, sendo vivido com diferentes graus de sofrimento emocional ${ }^{3}$. Um dos fatores que contribui para esse sofrimento é o fato de as primeiras experiências do estudante de Medicina serem marcadas por uma excessiva aquisição teórica do conhecimento nas "cadeiras básicas", o que mantém os alunos muito distantes da prática médica. Isto pode gerar, no futuro, dificuldades em conciliar as necessidades pessoais com aquelas relacionadas à formação profissional ${ }^{6}$, como, por exemplo, abrir mão do lazer, que não foi uma necessidade apenas até o vestibular, mas será para o resto da vida ${ }^{3}$.

As primeiras experiências dos estudantes de Medicina são muito importantes em seu aprendizado. Os primeiros pacientes com quem esses estudantes têm contato são, na maioria, indigentes cujos corpos foram doados ao laboratório de anatomia. Isto funciona como um primeiro modelo da relação médico-paciente ${ }^{7}$, e, portanto, essa primeira relação na faculdade é com um cadáver e não entre um ser humano vivo e outro vivo. Como defesa, observa-se aumento da euforia e da ansiedade pela exposição ao cadáver humano, e os alunos passam a se questionar como estes serão: afrodescendentes ou caucasianos, grandes ou pequenos, homem ou mulher, etc ${ }^{8}$. Outra defesa observada nesse momento é o fato de os alunos, frequentemente, reprimirem seus sentimentos sobre a morte durante a dissecção ${ }^{7}$. Marcus ${ }^{9}$, em seu estudo, buscou revelar o processo inconsciente desenvolvido durante a formação médica. Através de sonhos, mostrou que muitas fantasias ocorrem como uma defesa contra as inevitáveis e dolorosas ansiedades da adaptação emocional às experiências durante esse processo? ${ }^{9}$.

A relação médico-paciente, longe de ser uma simples relação "de homem para homem" ou, segundo a ideologia médica, "o encontro de uma consciência e uma confiança", é sempre uma relação de classe, sendo a atitude do médico modificada em função principalmente da classe social do doente $^{10}$. Os pacientes são particularmente sensíveis aos "modos" dos médicos e prontos a reparar em todas as nuances de sua atitude em relação a eles, em sua familiaridade, amabilidade, orgulho ou arrogância, talvez porque têm uma aguda consciência da distância entre eles: uma distância social ou devida a diferenças lexicológicas presentes na comunicação ${ }^{10}$.

Diante disso, é imprescindível o preparo emocional para que o estudante saiba lidar com a relação médico-paciente, 
considerada pelo filósofo francês Michel Foucault, essencialmente, uma relação de poder ou poder/conhecimento. Sabe-se, com efeito, que os médicos possuem conhecimentos, meios materiais e direito que lhes conferem muitos poderes e lhes dão a possibilidade de manipulação real ou fantasiada pelo paciente, o qual, muitas vezes, procura o médico já com preconceitos ou pré-julgamentos. Como a relação de força é demasiado desigual e para desmascarar tal manipulação ou evitá-la seria preciso ter poderes equivalentes aos do manipulador, os pacientes das classes populares não têm outros recursos para se defender e se assegurar senão a desconfiança e a caçoada, o mau humor e a suspeita ${ }^{11}$.

Dentre muitos fatores que contribuem para essa desconfiança é possível citar a comunicação ineficaz. O diálogo médico-paciente envolve poder, uma vez que é capaz de causar mudanças sociais, de pensamento e comportamento do paciente ${ }^{12}$. Freud já relatara que, quando se conversa com pacientes que possuem conflitos emocionais, estes podem ser expressos em sintomas e, portanto, o diálogo se mostra imprescindível ${ }^{13}$.

É necessário treinar o afeto do médico nas relações por ele estabelecidas, e isso depende de modelos de humanização durante o ensino médico. A graduação em Medicina exige um preparo técnico-relacional desenvolvido a partir de estudos teóricos e experiências assistenciais supervisionadas. Há muitas situações às quais os alunos são expostos, como lidar com pessoas doentes e suas ansiedades, conviver com a morte e limitações do conhecimento médico e do sistema de saúde, sendo tais experiências importantes na perspectiva do aluno em relação ao seu futuro profissional ${ }^{14}$.

Maheux et al. ${ }^{15}$ avaliaram de que modo os alunos de escolas tradicionais e inovadoras percebem seus professores como médicos humanistas. Concluíram que um número grande e inaceitável de alunos (mais de $40 \%$ ) não percebe que seus professores manifestam qualidades humanísticas nas relações com pacientes ou com alunos e não os entendem como um bom modelo no ensino da relação médico-paciente ${ }^{15}$. Para Martins ${ }^{16}$, "o ensino médico que não reflete sobre o ser humano que há no médico participa de modo altamente prejudicial nas deformações adaptativas do futuro profissional" (p. 363).

No desenrolar das atividades práticas em que o contato com o paciente se torna mais intenso e as situações mais complexas na relação médico-paciente vão surgindo, os estudantes lançam mão, consciente e inconscientemente, de maneiras para lidar com as dificuldades: observando a conduta de colegas e professores, revivendo experiências familiares e sociais, e, aos poucos, construindo suas próprias estratégias ${ }^{17}$. Novos currículos de Medicina vêm sendo implantados com o propósito de contribuir para a formação de profissionais que aten- dam às necessidades de saúde presentes e futuras da população, enfatizando a relevância social da medicina e do médico, seu compromisso ético e seu fundamento humanístico ${ }^{18}$, a fim de flexibilizar o enfrentamento ${ }^{17}$.

Em busca da aproximação progressiva do aluno à prática médica, mediante um conhecimento real de como se dão as relações médico-paciente nos diversos ambientes da área de saúde e de um aprimoramento do entendimento dos alunos sobre essa relação (a capacidade de observar, como um telespectador, os defeitos e qualidades a serem assimiladas dos encontros observados), a Universidade Federal de São Paulo (Unifesp) — Escola Paulista de Medicina introduziu, em 2003, no primeiro ano do curso médico, a disciplina de Observação da Prática Médica (OPM), respeitando as características tanto da instituição (campo físico de tal experiência), como as peculiaridades do campo emocional de estudantes e pacientes. Esse curso visa, além da apresentação de práticas aos iniciantes, à integração nos diversos níveis de conhecimento e experiência - biológico, psicológico e social - desde o início da formação médica, o que auxilia na internalização, pelo estudante, da concepção humanista de medicina ${ }^{19}$.

O módulo se inicia com a realização de um sociodrama na primeira semana de aula (semana do calouro) com o objetivo de levantar o perfil do estudante-calouro, suas expectativas, fantasias, medos e desejos. Essa atividade também aborda o papel do estudante ingressante no curso de Medicina e favorece a integração desse novo grupo no espaço físico da universidade ${ }^{19}$.

Essa disciplina possibilita ao aluno desenvolver a capacidade de observar, como um telespectador, os defeitos e qualidades a serem assimilados nos encontros observados, permitindo uma integração, desde o início da formação, entre a sala de aula e o campo de atuação médica. Desta forma, os estudantes de Medicina, em duplas, são observadores nos vários cenários do Complexo Assistencial da Unifesp, como o Programa Saúde da Família (PSF), Unidades Básicas de Saúde (UBS) e o próprio hospital universitário, o Hospital São Paulo, que inclui tanto os setores de dentro do hospital (Centros Obstétricos, por exemplo), quanto os atendimentos externos, em ambulatórios de especialidades (Geriatria, Genética Médica, Oftalmologia, entre outros). Essa observação é realizada em uma manhã por mês, durante quatro horas, sendo acompanhada por médicos que atuam no respectivo cenário, sem alterar a rotina do serviço. Os alunos seguem um roteiro com o objetivo de guiar a observação para detalhes como ambiente, equipe multiprofissional, relação médico-paciente e procedimentos realizados. Ao final da visita, os estudantes entrevistam o médico que os acompanhou com o intuito de se aproximar da realidade médica: formação, especialização, mercado de trabalho e sentimento do profissional quanto à profissão ${ }^{19}$. 
Na semana seguinte, divididos em turmas menores, os estudantes se encontram com os professores (de diversas especialidades) fixos em seu grupo para uma discussão aprofundada e elaboração das vivências julgadas relevantes. Esta divisão estudantes-professores é mantida durante todo o curso, de modo que cada subgrupo mantenha o vínculo professor-aluno, permitindo melhor aprofundamento das questões que surgem ${ }^{19}$. Nesse mesmo dia, os alunos devem entregar um relatório individual predominantemente descritivo, elaborado em casa e composto de duas partes: na primeira, são descritas tanto as impressões pessoais quanto a estrutura do cenário visitado, atividades desenvolvidas e, principalmente, considerações a respeito de si mesmo e das relações entre os profissionais de saúde, pacientes e acompanhantes; na segunda parte, é descrita a entrevista realizada com o médico ${ }^{19}$.

Após a discussão em subgrupos, estes são reunidos em grupos maiores com o intuito de compartilhar experiências, homogeneizar o aprendizado e avaliar as atividades. Ao final desta reunião, o aluno é orientado a elaborar um segundo relatório individual predominantemente reflexivo, aos 40 minutos finais do período de discussão, não apenas sobre sua visita, mas também sobre relatos das visitas de seus colegas ${ }^{19}$.

O objetivo do presente estudo foi avaliar a influência imediata e ao longo do tempo da disciplina OPM sobre a vivência prática dos graduandos de Medicina do primeiro ao terceiro ano da Unifesp, analisando a mudança na percepção desses alunos em relação à disciplina.

\section{MÉTODO}

O trabalho utilizou como ferramenta metodológica um questionário com cinco questões de múltipla escolha e três questões abertas, elaboradas pelos autores, tratando-se, portanto, de uma pesquisa de abordagem mista (qualitativa e quantitativa). Participaram 30 estudantes do primeiro ao terceiro ano da graduação médica da Unifesp (ano letivo de 2006), sendo dez de cada ano, sorteados aleatoriamente. Após submissão e aprovação do projeto pelo Comitê de Ética em Pesquisa, sob o protocolo $n^{\circ}$ 1.728/06, iniciou-se o estudo. Os acadêmicos sorteados foram convidados a participar do estudo após explicação sobre o conteúdo da pesquisa e esclarecidos quanto ao sigilo da mesma. Após concordarem em participar do trabalho, os alunos assinaram um Termo de Consentimento Livre e Esclarecido antes de responder às questões.

Os dados foram digitados em planilhas Excel 2000 for Windows, para adequado armazenamento e análise estatística das informações, sendo as questões abertas categorizadas após análise dos dois autores e consenso entre eles sobre as categorias.

\section{RESULTADOS E DISCUSSÃO}

O estudo constatou que para $68 \%$ dos alunos a disciplina OPM contribuiu para melhor conhecimento da estrutura da Unifesp, e para $19 \%$ foi significativa no acolhimento emocional. A diferença mais significativa foi observada do segundo para o terceiro ano, onde o conhecimento da estrutura passou de $60 \%$ para $80 \%$, e o acolhimento emocional passou de $30 \%$ para $10 \%$ (Gráfico 1 ).

\section{GRÁFICO 1}

A Disciplina "Observação de Práticas Médicas" (OPM) significou para os alunos

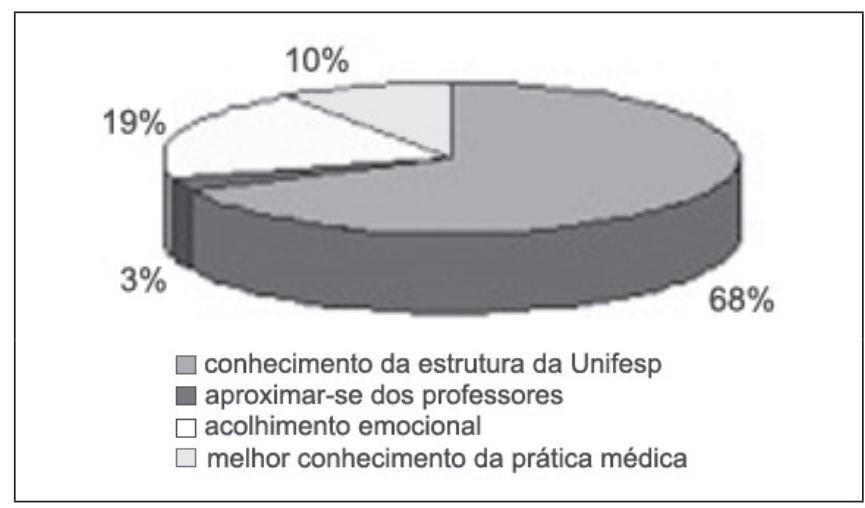

Quando questionados sobre a importância da OPM na formação do aluno, numa escala de 0 (menos importante) a 5 (mais importante), 37\% dos alunos responderam 3, 23\%, 2, e $20 \%, 4$, sendo que em nenhum dos anos a disciplina foi considerada sem importância alguma (nota 0). A nota 3 predominou no primeiro ano $(60 \%)$, e houve o aparecimento da nota máxima no segundo e terceiro ano (Gráfico 2).

GRÁFICO 2

A importância da OPM para os alunos

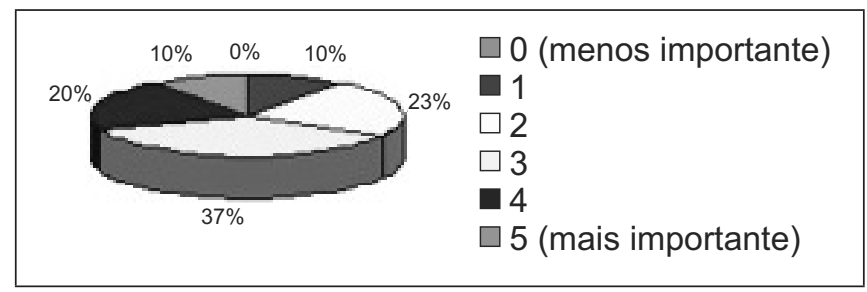

Quanto à contribuição da OPM para a atitude do aluno frente ao paciente, utilizando-se a mesma escala, 33\% dos alunos responderam 2, 27\%, 3, e 27\% responderam 4 . A avaliação melhorou com o passar dos anos, saindo dos $40 \%$ de nota 3 no primeiro ano para $50 \%$ de notas acima de 3 no terceiro ano (Gráfico 3). 
GRÁFICO 3

Contribuição da OPM para a atitude do aluno frente ao paciente

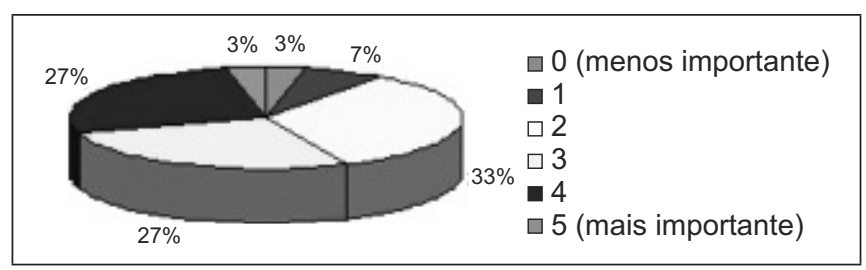

Quando questionados sobre o momento adequado da administração do curso de OPM, 87\% dos alunos das três séries pensam que o curso deve continuar sendo ministrado no primeiro ano da graduação, postura mais evidente com o avançar dos anos (Gráfico 4).

\section{GRÁFICO 4}

Momento adequado para a administração do curso OPM, segundo os alunos

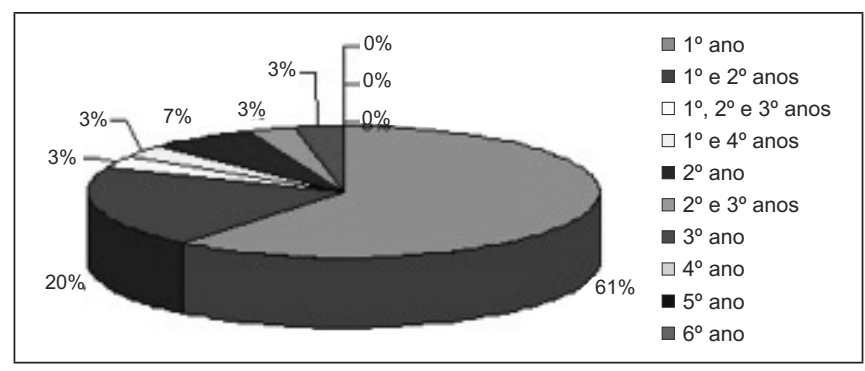

A OPM aumentou o conhecimento de: 70\% dos estudantes sobre a estrutura da Unifesp; $33 \%$ sobre os pacientes; $30 \%$ sobre os colegas e professores; $27 \%$ sobre si mesmo; e $17 \%$ sobre seu conhecimento médico (Gráfico 5).

\section{GrÁfico 5}

O curso OPM aumentou o conhecimento do aluno em relação a:

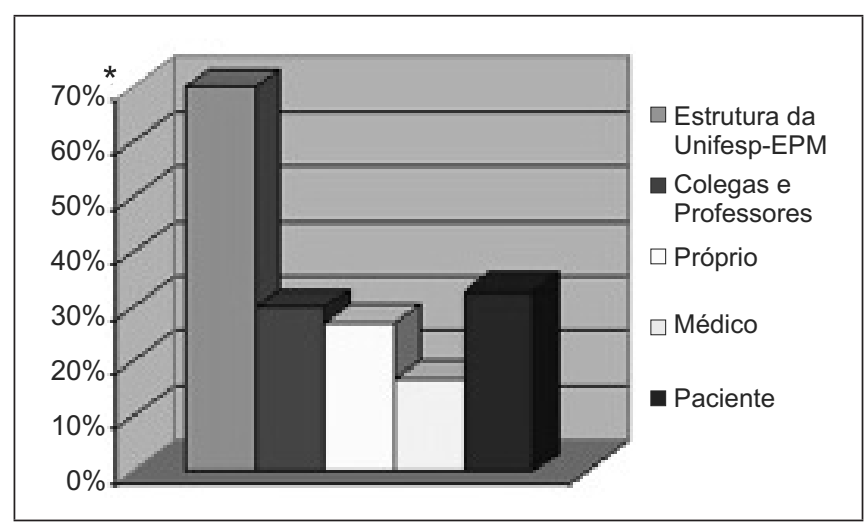

Para $40 \%$ dos entrevistados, a vivência que mais contribuiu para sua formação durante a disciplina foi a visita ao Centro Obstétrico, devido à ansiedade e curiosidade dos alunos nesse momento do curso, que relataram grande envolvimento emocional:

\begin{abstract}
“Eu já suspeitava e obtive confirmação de que passo mal em ambientes envoltos por maior tensão. Por isso, apesar de incoerente, gostei muito de minha visita ao centro cirúrgico e a $G O$, uma vez que conheci minha fraqueza e isso me estimulou a buscar meios (ex.: entrar em uma Liga que se dê nesses ambientes) para combater essa minha deficiência."

"A vivência que mais contribuiu foi a visita ao Hospital Vila Maria e ter a oportunidade de observar um parto, pois isso contribuiu para diminuir a ansiedade de querer saber, comum em graduandos do primeiro ano."
\end{abstract}

"A que mais contribuiu (pelo menos a que mais me marcou) foi quando eu vi um parto no Vila Maria, foi uma experiência incrível pra uma aluna do primeiro ano, mesmo porque até hoje não vi outro parto."

"A vivência que mais contribuiu para a minha formação foi quando visitamos a Obstetrícia. Conseguimos ver cinco partos (normais e cesáreas). Foi uma experiência enriquecedora, pois não precisamos do conhecimento técnico para aproveitarmos a visita. A ansiedade de um calouro de Medicina em se aproximar da prática médica foi saciada."

Foram citadas, também, como importantes para a formação as discussões após as visitas:

"As discussões pós-visita aos hospitais, de forma geral. Acredito que elas tornaram a visão dos alunos menos alienada."

Houve menção também ao conhecimento sobre o médico entrevistado, à relação médico-paciente e às visitas variadas, como ao Centro de Genética Médica:

\footnotetext{
"A que mais contribuiu foi observar a atitude do médico frente ao paciente."

"E tive contato com uma médica excelente, tanto como pessoa quanto como profissional."

"A vivência que mais contribuiu foi a observação de consultas no Centro de Genética Médica. Nessa visita, eu realmente pude observar o que é a relação médico-paciente: a conversa, o olhar e o escutar do(a) médico(a), a preocupação e dedicação em procurar o diagnóstico da doença e seu tratamento. Nessa visita, tive a oportunidade de entrar em contato com pessoas
} 
bastante humildes, algumas analfabetas, algumas desconhecem a própria data de nascimento. E embora já soubesse da existência dessa realidade, fiquei bastante chocada com ela e pude perceber que essa será uma das dificuldades do exercício da minha profissão."

Por outro lado, a vivência que menos contribuiu para sua formação foi visitar a UBS (17\%) e realizar discussão após as visitas $(13 \%)$.

"A que menos contribuiu foi uma vez que fui numa Unidade Básica de Saúde e não vi nenhum atendimento. Apenas conheci as dependências do local. Saí totalmente desiludida de lá."

"As experiências que contribuíram menos foram os relatórios $e$ as discussões em grupo. Embora o objetivo dessas duas atividades seja importante, ele não era cumprido com o exercício das mesmas. [...] Além disso, não me parece correto avaliar as sensações particulares dos alunos. Outro ponto negativo eram as discussões em grupo, que não acrescentavam muito, pois eram simplesmente a descrição daquilo que cada grupo tinha visto e sem sequer oferecer qualquer apoio emocional."

"Menos contribuiu: as discussões em sala eram extremamente enfadonhas e desnecessárias. Acabavam com o "brilho" da visita."

O objetivo do curso, para $43 \%$ dos alunos, foi proporcionar o conhecimento da prática médica; para $37 \%$, ter atividade prática em um curso essencialmente teórico; para $23 \%$, conhecer a relação médico-paciente; e para $23 \%$, conhecer a estrutura da Unifesp.

"O objetivo é que o aluno do primeiro ano, que está superansioso em conhecer o dia a dia médico, possa alcançar um pouco isso. Isto é superimportante, pois é o que o calouro mais anseia, e o fato de os dois primeiros anos de Medicina serem essencialmente teóricos é totalmente frustrante."

"Tornar a visão do aluno, que chega ainda alienado por conhecimentos especulativos sobre a medicina, mais realista e, até mesmo, menos preconceituosa acerca de alguns termos/ tabus médicos."

"Humanizar ainda mais o médico da EPM, pois no primeiro ano ainda nos colocamos na posição do paciente e conseguimos fazer uma análise da postura do médico."

"O objetivo deste curso é preparar mais os estudantes para lidar com pessoas, a se acostumar a considerar situações fora da sala de aula ou laboratório e mesmo diminuir o medo e a ansiedade com relação ao contato com o paciente quando já for um profissional formado."

\footnotetext{
"A proposta do curso parece ser expor o aluno à estrutura e ao funcionamento do hospital e do sistema de saúde e colocar o aluno em contato com as emoções e sensações que isso the causa."
}

A principal sugestão ao curso foi continuar a discussão após a visita (17\%), e a principal crítica foi a necessidade de elaborar relatórios na disciplina (17\%):
"Acredito que o curso OPM está muito bem estruturado. Os professores dedicam-se pacientemente a ouvir os depoimentos de todos os alunos nas discussões em grupos. Nessas discus- sões aprendemos um pouco como nossos colegas veem a pro- fissão e os pacientes, além de trocar informações sobre lugares que não visitamos."
"A realização de um segundo relatório (no dia da discussão) desnecessário."
"É obvio que a única maneira de nos avaliarem nesse módulo é através dos relatórios. Contudo, dois relatórios por visita [...] tornam-se enfadonhos. Porque os temas geralmente são os mesmos [...]."

\section{CONCLUSÃO}

Sabe-se que o aprendizado da medicina é difícil, dada sua amplitude. A medicina não é uma ciência biológica, mas, sim, uma sólida base de conhecimentos biomédicos indispensáveis ao seu pleno exercício. Também não é uma ciência exata, entretanto o diagnóstico e o tratamento devem ser baseados em evidências demonstráveis. Além disso, a medicina não é uma ciência humana, mas sem uma relação médico-paciente plena de compreensão e confiança ela não existiria ${ }^{19}$.

Este trabalho demonstrou que a disciplina OPM, ao proporcionar a aproximação progressiva dos alunos à prática médica, mostrando-lhes a realidade das relações médico-paciente nos diversos cenários visitados, permitiu a apresentação de práticas aos iniciantes e a integração nos diversos níveis de conhecimento e experiência - biológico, psicológico e social. Visitas ao Centro Obstétrico permitiram saciar uma ansiedade natural e comum dos iniciantes na área médica, aproximando-os de técnicas e cenas desconhecidas.

Além disso, observou-se uma modificação na percepção dos alunos a respeito do curso OPM sob diversos aspectos ao longo de sua formação. Por exemplo, o significado da OPM para eles mudou com o passar do tempo: enquanto os alunos de séries mais adiantadas valorizaram mais o conhecimento da estrutura da universidade por estarem no início do curso de semiologia e visitarem com mais frequência o ambiente 
hospitalar, os alunos das primeiras séries consideraram que a disciplina os acolheu mais emocionalmente.

Diante desses resultados, constatou-se que o curso OPM tem grande importância nos primeiros anos da graduação médica, oferecendo ao futuro médico o toque artístico que enriquecerá sua relação médico-paciente, contemplando o dizer de Drummond: "infundir ritmo ao puro desengonço"19 (p. 49).

\section{REFERÊNCIAS}

1. Jürgen T. O segredo dos médicos antigos. São Paulo: Melhoramentos; 1990.

2. De Marco MA, org. A face humana da medicina: do modelo biomédico ao modelo biopsicossocial. São Paulo: Casa do Psicólogo; 2003.

3. Ramos-Cerqueira ATA, Lima MC, Pereira MC. A formação da identidade do médico: implicações para o ensino de graduação em medicina. Interface Comun Saúde Educ. 2002;6(11):107-16.

4. Alves R. O médico. Campinas: Papirus; 2003.

5. Manente MLF. A opção pela Medicina: determinantes psicossociais. São Paulo; 1992. Mestrado [Dissertação] — Universidade Federal de São Paulo.

6. Avancine MATO. Medos, atitudes e convicções de estudantes de medicina perante a doença. São Paulo; 1994. Mestrado [Dissertação] — Universidade Federal de São Paulo.

7. Vora A. An Anatomy Memorial Tribute: Fostering a Humanistic Practice of Medicine. J Palliat Med. 1998;1(2):117-22.

8. Swartz WJ. Using gross anatomy to teach and assess professionalism in the first year of medical school. Clin Anat. 2006;19(5):437-41.

9. Marcus ER. Medical student dreams about medical school: The unconscious developmental process of becoming a physician. Int J Psichoanal. 2003;84(Pt 2):367-86.

10. Boltanski L. As Classes Sociais e o Corpo. Rio de Janeiro: Paz e Terra; 2004.

11. Nogueira-Martins LA, Nogueira-Martins MCF. O exercicio atual da Medicina e a relação médico-paciente. Rev Bras Clín Ter.1998;24(2):59-64.

12. Hanna M, Fins JJ. Viewpoint: Power and Communication: Why Simulation Training Ought to Be Complemented by Experiential and Humanist Learning. Acad Med. 2006;81(3):265-70.

13. Kalb C. The Therapist as Scientist. Newsweek [on line].2006. [acesso em 09 out. 2009]; [cerca de 2 p.]. Disponível em: http:/ / www.newsweek.com/id/46978.

14. Mascia AR, Silva FB, Lucchese AC, De Marco MA, Nogueira-Martins MCF, Nogueira-Martins LA. Atitudes frente a aspectos relevantes da prática médica: estudo transversal randomizado com alunos de segundo e sexto anos. Rev Bras Educ Med. 2009;33(1):40-8.

15. Maheux B, Beaudoin C, Berkson L, Côté L, Marchais JD, Jean P. Medical faculty as humanistic physicians and teachers: the perceptions of students at innovative and traditional medical schools. Med Educ. 2000;34(8):630-4.

16. Nogueira-Martins LA. Atividade médica: fatores de risco para a saúde mental do médico. Rev Bras Clin Ter. 1991;20:355-64.

17. Silva LCG, Rodrigues MMP. Eventos estressantes na relação com o paciente e estratégias de enfrentamento: estudo com acadêmicos de medicina. J Bras Psiquiatr. 2004;53(3):185-96.

18. Campos JJB, Komatsu R. Novos currículos de Medicina na FAMEMA e na UEL: uma construção permanente rumo à realidade presente e futura. Olho Mágico [periódico na internet]. 2001 [acesso em 09 out. 2009]; 8(2):8-10. Disponível em: http:/ /www.ccs.uel.br/olhomagico/v8n2/Joao2.htm

19. Puccini RF, Sampaio LO, Batista NA. A formação médica na Unifesp: excelência e compromisso social. São Paulo: Unifesp; 2008.

\section{CONTRIBUIÇÃO DOS AUTORES}

Danielle Bianchini Rampim participou da elaboração do estudo, criação dos questionários e submissão do trabalho ao Comitê de Ética, auxiliou na seleção dos participantes, na aplicação dos instrumentos, análise dos resultados e na redação do artigo. Juliana Augusta Plens de Moura Garcia participou da elaboração do estudo, redigindo-o, criando os questionários e submetendo o trabalho ao Comitê de Ética, auxiliou, também, na seleção dos participantes, na aplicação dos instrumentos, análise dos resultados e na redação do artigo. Paulo Schor participou do delineamento do estudo, análise e interpretação dos resultados e da redação do artigo. Julieta Freitas Ramalho da Silva participou da análise e interpretação dos resultados e auxiliou na elaboração do artigo e na elaboração do estudo.

\section{CONFLITO DE INTERESSES}

Declarou não haver.

\section{ENDEREÇO PARA CORRESPONDENCIA}

Juliana Augusta Plens de Moura Garcia

Rua Embaú, 206 apt.11

Vila Clementino - São Paulo

CEP. 04039-060 SP

E-mail: juliplens@gmail.com 